\title{
SINKRONISASI KEBIJAKAN NASIONAL REDD+ DENGAN KEPENTINGAN PARA PIHAK PADA TINGKAT SUBNASIONAL
}

(Synchronization of REDD+ National Policy with Stakeholders' Interest in Subnational Level)

\author{
Mimi Salminah \& Ari Wibowo \\ Pusat Penelitian dan Pengembangan Sosial, Ekonomi, Kebijakan dan Perubahan Iklim, \\ Badan Litbang dan Inovasi, Kementerian Lingkungan Hidup dan Kehutanan, \\ Jl. Gunung Batu No. 5, Bogor, 16118, Indonesia \\ E-mail:mimiaruman@yahoo.com.sg, ariwibowo61@yahoo.com
}

Diterima 28 April 2017, direvisi 16 Oktober 2017, disetujui 16 Oktober 2017.

\begin{abstract}
REDD+ has been developed since 2007, but its implementation has not been run effectively. Synchronizing all related stakeholders' interest, either horizontally or vertically becomes major challenge to support the effectiveness $R E D D+$ implementation. The result of the gap analysis showed that unsynchronized REDD+ national policy with stakeholders' interest in subnational and site level lead to ineffective REDD+ implementation. This is particularly when REDD + is developed through subnational approach by which provincial government plays as a main actor in its implementation. For instance, ban of carbon market system has caused some REDD+ projects in the site level initiated by private sector to be stagnant. Enabling conditions should be built up to synchronize related stakeholders' interest in all levels. The aforementioned conditions are including simplified REDD+ regulations so that REDD + can be adopted, existance of regional REDD+ institutions to bridge communication between central and provincial government, clear domestic funding and incentive mechanism to deal with uncertainty global agreement, as well as increasing outreach of REDD+ strategies and policies in sub-national and site levels.
\end{abstract}

Keywords: Unsynchronized of policy; provincial government; effective; incentive mechanism; global agreement.

\begin{abstract}
ABSTRAK
REDD+ telah diinisiasi sejak tahun 2007 tetapi sampai saat ini pelaksanaannya belum berjalan secara efektif. Sinkronisasi kepentingan para pihak yang terlibat baik secara vertikal maupun horizontal menjadi tantangan besar untuk mendukung efektivitas pelaksanaan REDD+. Analisis gap pada penelitian ini menunjukkan bahwa terdapat ketidaksinkronan antara kebijakan REDD + di tingkat nasional dengan kepentingan para pihak di tingkat subnasional dan tapak. Hal tersebut menjadi penghambat pelaksanaan REDD + di lapangan, khususnya ketika pendekatan REDD+ yang dilakukan adalah pendekatan subnasional dimana pemerintah provinsi menjadi aktor penting dalam pelaksanaan REDD+. Sebagai contoh, pelarangan sistem pasar karbon di Indonesia telah menyebabkan beberapa proyek REDD + di tingkat lapangan yang diinisiasi pihak swasta mengalami stagnasi. Sinkronisasi kebijakan REDD+ nasional dengan kepentingan para pihak dapat diwujudkan apabila kondisi pemungkinnya sudah terbangun. Adapun kondisi pemungkinnya adalah peraturan teknis dan administratif REDD+ yang mudah untuk diadopsi oleh para entitas REDD+ sesuai dengan kondisi di lapangan, tersedianya institusi pelaksana REDD+ yang jelas di tingkat subnasional, adanya mekanisme pendanaan dan insentif dalam negeri untuk mengantisipasi ketidakpastian kesepakatan global serta peningkatan sosialisasi strategi dan kebijakan REDD+ ke daerah.
\end{abstract}

Kata kunci: Ketidaksinkronan kebijakan; pemerintah daerah; efektif; mekanisme insentif; kesepakatan global. 


\section{PENDAHULUAN}

Upaya mitigasi perubahan iklim melalui program Reducing Emission from Deforestation and Degradation (REDD) yang kemudian memasukkan konservasi, sustainable forest management (SFM) dan peningkatan stok karbon sebagai REDD+ telah diinisiasi sejak tahun 2007. Berbagai isu terkait rumusan pelaksanaan REDD + telah didiskusikan dan dinegosiaikan antar negara yang berkepentingan.

Perkembangan kebijakan REDD+, implementasinya di lapangan termasuk aktor yang terlibat, serta dampak pelaksanaannya berkembang menjadi topik sentral REDD+ (Angelsen et al., 2009; Angelsen \& McNeill, 2012; Gupta, Van der Grijp, \& Kuik, 2013; Levin, McDermott, \& Cashore, 2008). Vijge, Brockhaus, Di Gregorio, and Muharrom (2016) menggarisbawahi empat pertanyaan spesifik terkait program REDD+ yaitu

Apa yang seharusnya dicapai REDD+? (2) Siapa yang seharusnya memonitor hasil dan dampak pelaksanaan REDD+? (3) Pada level apa REDD+ sebaiknya dilaksanakan? Dan (4) Mekanisme pembiayaan seperti apa yang sesuai untuk pelaksanaan REDD+?

Pelaksanaan REDD + di Indonesia dibagi menjadi tiga tahap. Tahap 1 (tahap persiapan/ preparation phase) difokuskan pada upaya identifikasi status ilmu pengetahuan dan teknologi(IPTEK)dankebijakanterkait(20072008); tahap 2 (readiness phase) merupakan tahap penyiapan perangkat metodologi dan kebijakan REDD+ (2009-2012); sedangkan tahap 3 (full implementation) merupakan tahap implementasi penuh sesuai aturan Conference of the Parties/COP (mulai tahun 2013) (Nurtjahjawilasa, Duryat, Ysman, Septiani, \& Lasmini, 2013).

Readiness phase memegang peran penting dalam mendukung pelaksanaan penuh REDD+ di Indonesia. Berdasarkan dokumen Strategi REDD Indonesia (Departemen Kehutanan, 2010) strategi readiness phase REDD+ meliputi intervensi kebijakan dan penyiapan regulasi REDD, penyiapan aspek metodologi REL/RL (Reference Emission Level/Reference Level) dan MRV (measuring, reporting dan verification), penyiapan/ penguatan kelembagaan REDD+, serta pembangunan Demonstration Activities (DA)-REDD.

Dalam konteks pembangunan REDD+ secara fisik di lapangan, pada awal-awal tahun pengembangan, antusiasme untuk membangun DA REDD+ sangat tinggi. Venter and Koh (2012) mencatat DA REDD+ yang aktif di Indonesia sebanyak 21 pelaksana. Kemudian, Dewan Nasional Perubahan Iklim (DNPI) mencatat kenaikan menjadi sebanyak 70 DA REDD+ di berbagai tipe ekosistem hutan. Sayangnya, hampir seluruh pembangunan DA REDD+ mengalami stagnasi (Wibowo \& Salminah, 2016). Data tahun 2016 Direktorat Jenderal Pengendalian Perubahn Iklim (Ditjen PPI) sebagai focal point program pengendalian perubahan iklim menunjukkan jumlah DA REDD+ menurun menjadi sekitar 32 tanpa diketahui dengan jelas perkembangan kegiatannya.

Perjalanan panjang REDD+ di Indonesia dengan hasil yang belum menampakan keberhasilan, mengindikasikan suatu hipotesis bahwa terdapat kebijakan REDD+ di tingkat pusat yang tidak sesuai dengan kondisi dan kepentingan para pihak di tingkat tapak. Ketidaksesuaian tersebut mengakibatkan program REDD+ sulit untuk dilaksanakan secara efektif khususnya di lapangan. Luttrell, Resosudarmo, Muharrom, Brockhaus, and Seymour (2014) menyatakan bahwa pelaksanaan REDD+ di Indonesia memerlukan keterlibatan dan rasa memiliki yang kuat dari para pelaku kunci pengelolaan hutan baik di tingkat nasional maupun lokal. Sementara Angelsen et al. (2009) menggarisbawahi bahwa tantangan terbesar REDD+ nasional adalah pemaduan berbagai stakeholder dan sektor baik secara vertikal maupun horizontal.

Strategi pendekatan pelaksanaan REDD+ 
yang dilakukan Pemerintah Indonesia adalah pada tingkat subnasional (Departemen Kehutanan, 2010) yang berarti kegiatan REDD+ dilaksanakan pada wilayah dengan batas geografis tertentu, atau dapat dilakukan sebagai proyek oleh individu, masyarakat, lembaga non-pemerintah, perusahaan swasta atau pemerintah daerah dan nasional (Nurtjahjawilasa et al., 2013). Oleh karena itu, salah satu faktor kunci yang dapat mempercepat pelaksanaan REDD + adalah keselarasan antara kepentingan para pihak di level subnasional dengan kebijakan REDD+ di tingkat nasional.

Tulisan ini bertujuan untuk memberikan informasi tentang kebijakan REDD + di tingkat nasional, perkembangan implementasi di lapangan serta menganalisis kemungkinan adanya ketidaksinkronan antara kebijakan REDD+ yang dirumuskan pada tingkat nasional dengan kepentingan para pihak pada level subnasional. Informasi gap antara kebijakan REDD+ di tingkat nasional dengan kepentingan para pihak di tingkat subnasional maupun tapak dapat dimanfaatkan sebagai bahan pertimbangan untuk perumusan kebijakan REDD+ yang efektif dan dapat diterima oleh para pihak terkait. Penelitian ini juga penting untuk memberikan masukan terhadap konsep "best practices" kerja sama dan arsitekturglobal REDD+, yang seharusnya disesuaikan dengan kondisi di tingkat tapak. Review terhadap strategi REDD+ di negaranegara Asia-Pasifik yang dilakukan oleh ADB (2010) menyimpulkan bahwa diperlukan perbaikan dalam mekanisme bantuan global REDD+ serta diperlukan pertukaran informasi antar-negara Asia-Pasifik terkait pelaksanaan REDD+ untuk mempercepat pencapaian tujuan REDD+ pada tingkat global.

\section{METODE PENELITIAN}

\section{A. Kerangka Pikir}

Pelaksanaan REDD+ di Indonesia melibatkan berbagai aktor baik di tingkat lokal maupun nasional (Barr et al., 2006;
Colfer, Dahal, \& Capistrano, 2008; Moeliono, Wollenberg, \& Limberg, 2009). Purnomo, Suyamto, Abdullah, \& Irawati (2012) menyatakan bahwa pelaksanaan REDD+ yang kompleks memerlukan keterlibatan berbagai pihak baik pemerintah, masyarakat, maupun swasta di tingkat pusat maupun lokal.

Stakeholder yang terlibat dalam formulasi kebijakan dan pelaksanaan REDD+ dapat dikategorikan menjadi tiga berdasarkan level atau skala ruang, yaitu pada level nasional yaitu pemerintah pusat, pada level subnasional yaitu pemerintah provinsi, dan pada level lokal/ tapak yaitu para pelaksana teknis REDD + di lapangan seperti taman nasional, Kesatuan Pengelolaan Hutan (KPH), masyarakat adat, atau para pemegang konsesi pengelolaan hutan. Masing-masing stakeholder memiliki kewenangan dan kepentingan yang berbedabeda.

Untuk mewujudkan pelaksanaan REDD+ yang efektif memerlukan komitmen dan perubahan perilaku dari berbagai pihak yang terlibat serta diperlukan mekanisme insentif REDD+ yang jelas (Purnomo et al., 2012). Para aktor yang terlibat harus mensinkronkan masing-masing kepentingan agar pelaksanaan REDD+ dapat memberikan manfaat optimal. Untuk menganalisis gap kebijakan dan implementasinya, setiap kewenangan dan kepentingan di setiap skala ruang diidentifikasi dan dianalisis untuk melihat ketidaksinkronannya. Proses sinkronisasi kewenangan dan fungsi masing-masing stakeholder seperti dalam Gambar 1 menentukan tercapainya efekivitas pengembangan REDD + di Indonesia.

\section{B. Pengumpulan data}

Data yang dikumpulkan berupa data primer dan data sekunder. Data primer meliputi observasi langsung dan wawancara (in depth interview) dengan stakeholder di tingkat pusat (Kementerian Lingkungan Hidup dan Kehutanan/KLHK), di tingkat provinsi pemerintah daerah (Pemda) dan pengelola demonstration activities (DA) REDD + di 


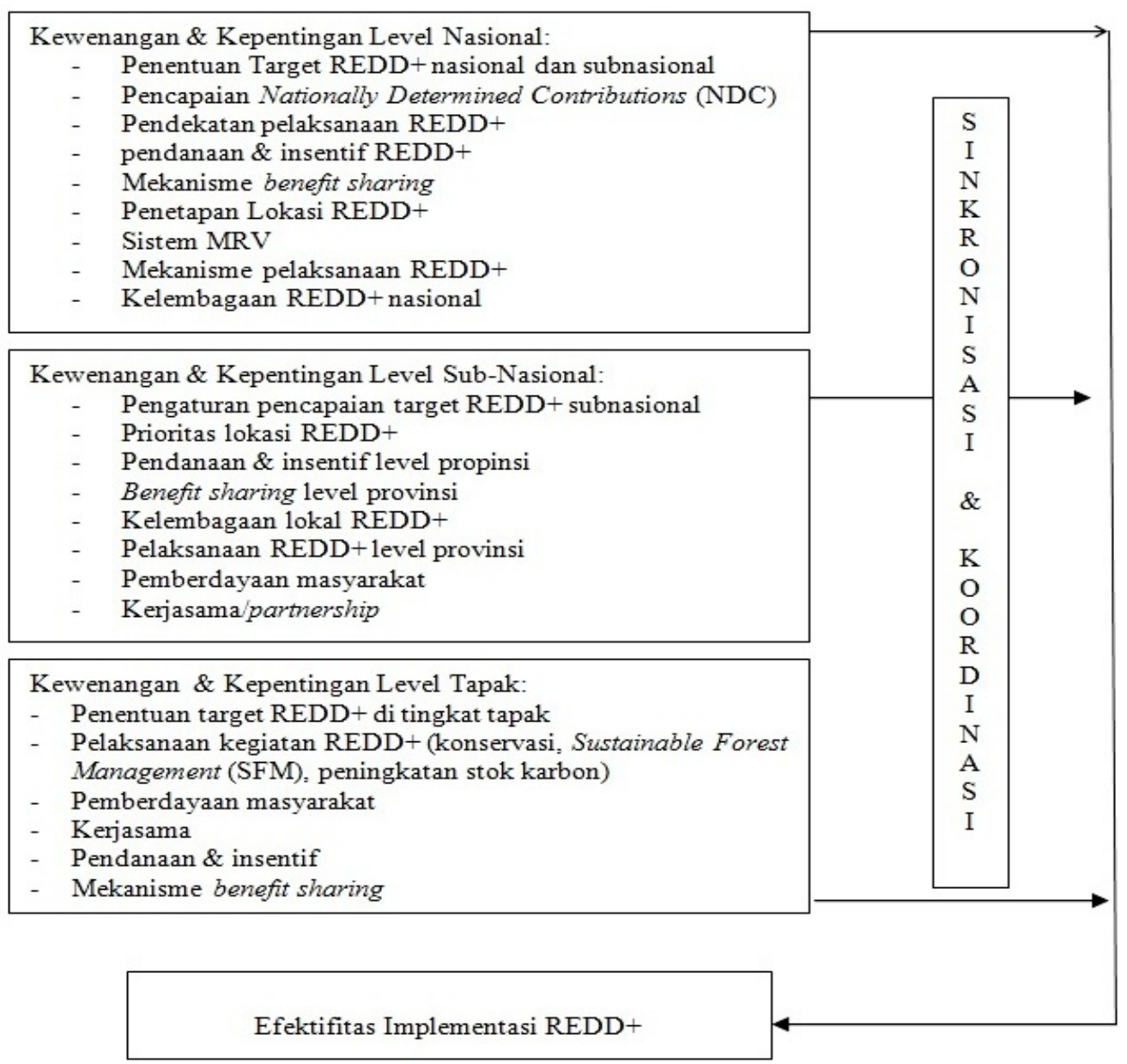

Sumber (Source): Indonesia REDD+ Task Force (diolah), 2012.

Gambar 1. Kerangka Pikir Penelitian.

Figure 1. Research Logical Framework.

lapangan. Data sekunder adalah berbagai dokumen kebijakan terkait REDD+ yang telah dikeluarkan oleh pemerintah pusat maupun pemerintah daerah, laporan, dan referensi yang berkaitan dengan kegiatan kajian, yang diperoleh dari studi literatur, data dari instansi atau lembaga terkait. Data yang dikumpulkan adalah informasi terkait REDD+, DA REDD+, berbagai peraturan perundangan di tingkat nasional dan global serta berbagai laporan pelaksanaan DA REDD+ di tingkat tapak.

Pengambilan data dikonsentrasikan pada sepuluh pelaksana yang melakukan kegiatan terkait REDD+ di berbagai tipe hutan, yaitu DAREDD+ di Hutan Kemasyarakatan (HKm) Aek Bual Lombok Barat, DA REDD+ KPHP
Boalemo Gorontalo, DA REDD+ Taman Nasional (TN) Meru Betiri Jawa Timur, DA REDD+ TN Bromo Tengger Semeru, DA REDD+ TN Sebangau Kalimantang Tengah, DA REDD+ TN Berbak Jambi, REDD+ PT Global Alam Lestari, DA REDD+ PT Rimba Raya Conservation, DA REDD+ PT Rimba Makmur Utama, DA REDD+ Tasik Serkap Riau, DA REDD+ Forest Carbon Partnership Facility (FCPF) Kalimantan Timur.

\section{Analisis}

Analisis data dilakukan secara deskriptif kualitatif untuk memberikan gambaran tentang berbagai kebijakan dan peraturan yang telah dikeluarkan di tingkat nasional dan 
pelaksanaan kegiatan di lapangan. Metode analisis kualitatif dipilih dengan pertimbangan metode tersebut lebih menekankan kepada analisis makna pada kondisi obyek yang alamiah dari pada menggenaralisasi (Sugiyono, 2008). Hal tersebut dinilai sesuai untuk menganalisis perkembangan REDD + yang sangat dinamis dan melibatkan banyak aktor. Analisis gap dilakukan untuk menganalisis gap antara kebijakan dengan pelaksanaannya di lapangan. Gap analysis biasa digunakan untuk mengevaluasi kebijakan dalam manajemen ekosistem, mengidentifikasi gap antara kebijakan dengan implementasinya, serta untuk merumuskan rekomendasi dalam rangka "filling the gaps" dalam manajemen ekosistem (Avishek, Yu, \& Liu, 2012).

\section{III.HASIL DAN PEMBAHASAN}

\section{A. Kebijakan dan Peraturan REDD+ di Tingkat Nasional}

Sejak dirumuskannya program REDD+ pada tahun 2007, pemerintah telah menyiapkan berbagai perangkat dan infrastruktur dalam rangka menuju pelaksanaan penuh REDD+. Berbagai peraturan untuk mendukung teknis pelaksanaan REDD+ telah dikeluarkan sebagaimana seperti pada Tabel 1 .

Penyelenggaraan DA REDD+ secara teknis juga harus mengikuti petunjuk internasional dari keputusan COP berupa International Guidance for $D A$ (Indicative guidance for DA: Annex of Dec. 2 / CP. 13). Selain itu, penyelenggaraan DA REDD+ di Indonesia harus memenuhi persyaratan yang ditetapkan Pemerintah Indonesia yaitu harus mewakili berbagai kondisi bio-geografi, mendapat dukungan dari pemerintah daerah, adanya ancaman terhadap hutan, adanya manfaat lain selain karbon yaitu manfaat keanekaragaman hayati dan manfaat terhadap masyarakat.

Sebagai pengaman penyelenggaraan REDD+, peraturan internasional mewajibkan setiap negara pelaksana REDD+ untuk menyusun sistem informasi safeguard
REDD+ yang mencakup tujuh komponen. Tujuan diterapkannya pengaman (safeguard) lingkungan dan sosial adalah untuk mencegah agar kegiatan REDD+ tidak mengakibatkan kerusakan terhadap lingkungan dan masyarakat yang ada di sekitarnya seawal mungkin pada tahap perencanaan.

Peraturan teknis REDD+ sangat detail, rigid dan pelaksanaannya memerlukan biaya yang signifikan. Di sisi lain, pendanaan dan kapasitas pemerintah daerah serta masyarakat sebagai pelaksana REDD+ di lapangan sangat terbatas. Hal tersebut menimbulkan kontraproduktif dengan tujuan pelaksanaan REDD+. Luttrell, Sills, Aryani, Ekaputri, and Evnike (2016) mengungkapkan bahwa aktor di level subnasional menanggung biaya yang sangat besar untuk pelaksanaan REDD + . Dengan demikian, keterbatasan dana dan kapasitas para pelaku di level subnasional untuk memenuhi aturan teknis REDD+ diindikasikan menjadi salah satu hambatan pelaksanaan REDD+. Pada kenyataannya, program-program yang diklaim sebagai REDD + , pada umumnya mengalami kesulitan sehingga belum memenuhi persyaratan teknis yang ditetapkan pemerintah.

Dari sisi kelembagaan, pembentukan kelembagaan REDD+ di level nasional mulai diinisiasi pada tahun 2010 dengan dibentuknya Satuan Tugas (Satgas) Persiapan REDD+ melalui Keputusan Presiden (Kepres) Nomor 19 tahun 2010. Hal tersebut merupakan implementasi komitmen kerja sama Indonesia dengan Norwegia dalam rangka penurunan emisi di sektor kehutanan. Pada tahun 2013 Badan Pengelola (BP) REDD+ dibentuk berdasarkan Peraturan Presiden (Perpres) Nomor 62 tahun 2013 sebagai hasil kerja Satgas REDD+. BP REDD+ memfokuskan kegiatan REDD+ di 11 provinsi dengan mempertimbangkan potensi penurunan emisinya. Kesebelas provinsi tersebut adalah Kalimantan Tengah, Kalimantan Timur, Jambi, Sumatera Barat, Sulawesi Tengah, Aceh, Papua, Riau, Papua Barat, Sumatera Selatan, dan Kalimantan Barat. Pembentukan 
Tabel 1. Peraturan terkait pelaksanaan REDD+ yang dikeluarkan Pemerintah

Table 1. REDD+ related regulations issued by the Government

\begin{tabular}{|c|c|c|}
\hline $\begin{array}{l}\text { No. } \\
\text { No. }\end{array}$ & $\begin{array}{c}\text { Nomor \& Jenis Peraturan } \\
(\text { No \& type of the regulation })\end{array}$ & Isi (Substance) \\
\hline 1. & $\begin{array}{l}\text { Peraturan Menteri Kehutanan (Permenhut) Nomor } \\
\text { P.68/Menhut-II/2008 tentang Penyelenggaraan } \\
\text { Demonstration Activities Pengurangan Emisi } \\
\text { Karbon dari Deforestasi dan Degradasi Hutan }\end{array}$ & Tata cara pelaksanaan DA REDD + \\
\hline 2. & $\begin{array}{l}\text { Permenhut Nomor P.30/ Menhut-II/2009 tentang } \\
\text { Tata Cara Pengurangan Emisi dari Deforestasi dan } \\
\text { Degradasi Hutan }\end{array}$ & Tata cara pelaksanaan REDD+ \\
\hline 3. & $\begin{array}{l}\text { Standar Nasional Indonesia (SNI) 7645: } 2010 \\
\text { tentang klasifikasi penutupan lahan }\end{array}$ & Penghitungan data historis perubahan penutup lahan \\
\hline 4. & $\begin{array}{lcrr}\text { SNI 7725: } 2011 \text { tentang } & \text { Penyusunan } \\
\text { Persamaan. Alometrik } & \text { untuk } & \text { Penaksiran } \\
\text { Cadangan Karbon Hutan } & & \\
\end{array}$ & Pengukuran dan penghitungan cadangan karbon \\
\hline 5. & $\begin{array}{l}\text { Peraturan Pemerintah (PP) Nomor } 61 \text { tahun } 2011 \\
\text { tentang Rencana Aksi Nasional Penurunan Emisi } \\
\text { Gas Rumah Kaca }\end{array}$ & $\begin{array}{l}\text { Rencana Aksi Nasional Penurunan Emisi Gas } \\
\text { Rumah Kaca (RAN-GRK), 88\% kegiatan } \\
\text { penurunan emisi nasional berasal dari REDD+ }\end{array}$ \\
\hline 6. & $\begin{array}{l}\text { Peraturan Presiden (Perpres) Nomor } 71 \text { tahun } \\
2011 \text { tentang. Penyelenggaraan Inventarisasi Gas } \\
\text { Rumah Kaca (GRK) Nasional }\end{array}$ & Metode inventarisasi GRK \\
\hline 7. & $\begin{array}{l}\text { Permenhut Nomor P.20/Menhut-II/2012 tentang } \\
\text { Penyelenggaraan Karbon Hutan }\end{array}$ & $\begin{array}{l}\text { Penyelenggaraan karbon hutan yang mengijinkan } \\
\text { perusahaan penyelenggara karbon hutan utuk } \\
\text { menjual pengurangan emisinya maksimal } 49 \% \text { ke } \\
\text { pihak atau negara lain }\end{array}$ \\
\hline 8. & $\begin{array}{l}\text { Permenhut Nomor P.11/Menhut-II/ } 2013 \text { tentang } \\
\text { Perubahan atas Permenhut Nomor 36/Menhut- } \\
\text { II/2009 tentang Tata Cara Perizinan Usaha } \\
\text { Pemanfaatan Penyerapan dan/atau Penyimpanan } \\
\text { Karbon pada Hutan Produksi dan Hutan Lindung }\end{array}$ & $\begin{array}{l}\text { Perubahan mekanisme perizinan usaha pemanfaatan } \\
\text { penyerapan dan/atau penyimpanan karbon pada } \\
\text { hutan produksi dan hutan lindung }\end{array}$ \\
\hline 9. & $\begin{array}{l}\text { Permenhut P.50/Menhut-II/2014 tahun } 2014 \\
\text { tentang Perdagangan Sertifikat Penurunan Emisi } \\
\text { Karbon Hutan }\end{array}$ & $\begin{array}{l}\text { Perdagangan sertifikat penurunan emisi karbon } \\
\text { hutan indonesia }\end{array}$ \\
\hline 10. & $\begin{array}{l}\text { Undang-Undang (UU) Nomor } 16 \text { tahun } 2016 \\
\text { tentang Pengesahan Paris Agreement to the } \\
\text { United Nations Framework Convention on } \\
\text { Climate Change }\end{array}$ & $\begin{array}{l}\text { Pengesahan Paris Agreement yang mengukuhkan } \\
\text { posisi REDD+ sebagai sebuah pendekatan kebijakan } \\
\text { dan insentif positif untuk aktivitas penurunan emis } \\
\text { dari hutan termasuk melalui pembayaran berbasis } \\
\text { hasil }\end{array}$ \\
\hline
\end{tabular}

Sumber (Source): Dari berbagai sumber peraturan, diolah (From various sources of regulation, processed).

BP REDD+ di tingkat nasional diikuti oleh pembentukan BP REDD+ daerah di tingkat provinsi. BP REDD+ daerah berfungsi untuk menjembatani komunikasi antara pemerintah daerah dan pemerintah pusat serta untuk memdukung pemerintah daerah dalam pelaksanaan kebijakan REDD + di tingkat tapak.

Presiden terpilih pada akhir tahun 2014 membawa kebijakan baru tentang perubahan iklim. Pada tahun 2015 BP REDD+ dibubarkan, sedangkan tugas dan fungsinya dilimpahkan kepada Direktorat Jenderal Pengendalian Perubahan Iklim (Dirjen PPI) di bawah Kementerian Lingkungan Hidup dan Kehutanan (KLHK). Dibubarkannya BP REDD+ nasional memberikan dampak negatif terhadap $\mathrm{BP}$ REDD + daerah. BP 
REDD + daerah di beberapa provinsi juga dibubarkan. Hal ini menyebabkan komunikasi dan sosialisasi kebijakan REDD+ nasional ke tingkat subnasional menjadi terhambat.

Selain itu, di bawah kepemimpinan baru Pemerintah Indonesia meratifikasi Paris Agreement (PA) pada COP 21 tahun 2016. Indonesia menyerahkan Nationally Determined Contribution (NDC) yang menyatakan komitmen nasional untuk menurunkan emisi sebesar $29 \%$ berdasarkan upaya swadaya dan $41 \%$ jika ada bantuan internasional dibandingkan skenario business as usual (BAU) pada tahun 2030.

Untuk memonitor pencapaian target 29\% dan $41 \%$, pada bulan November 2016 Dirjen PPI me-launching Sistem Registri Nasional (SRN). Melalui SRN, seluruh proyek terkait penurunan emisi harus diregistrasi secara nasional. SRN diklaim oleh pemerintah sebagi alat untuk memonitor dan memverifikasi proyek penurunan emisi di seluruh sektor di Indonesia termasuk REDD+. Meskipun demikian, SRN belum berjalan efektif karena belum ada peraturan yang mewajibkan penyelenggara REDD+ untuk melakukan registrasi.

Berdasarkan wawancara dengan stakeholder di KLHK, kebijakan insentif untuk REDD+ pasca PA difokuskan terhadap insentif yang berasal dari negara-negara maju sesuai dengan kesepakatan dalam PA artikel 5 yaitu melalui mekanisme performance based payment. Dengan demikian, mekanisme perdagangan karbon bukan merupakan kebijakan pemerintah untuk program REDD+. Selain itu, pemerintah menggariskan bahwa program penurunan emisi di Indonesia diutamakan untuk memenuhi target NDC bukan untuk perdagangan karbon. Meskipun demikian kebijakan tersebut belum diformalkan ke dalam peraturan yang lebih mengikat.

Kebijakan pelarangan perdagangan karbon di sektor lahan dapat dipahami mengingat hal tersebut tertera dalam kesepakatan global. Meskipun demikian masih terdapat perbedaan persepsi antar negara tentang mekanisme insentif untuk REDD+ termasuk performance based payment. Selain itu mekanisme performance based payment dinilai tidak sesuai untuk Indonesia karena sering membatasi kepemilikan dan dukungan internal (Human Rights Watch, 2009). Lebih jauh, Luttrell et al. (2014) menyatakan REDD+ harus memasuki mekanisme pasar internasional agar lebih transparan dan dapat dipertanggungjawabkan pelaksanaannya. Pada tingkat tapak, kebijakan pelarangan perdagangan karbon menyebabkan program REDD+ yang telah dinisiasi pihak swasta menjadi stagnan.

Untuk menghadapi ketidakpastian mekanisme insentif dalam REDD+ seharusnya para pihak di level nasional dapat memberikan alternatif insentif, misalnya domestic emission trading system seperti yang dikembangkan di negara-negara maju. Mekanisme lain yang dapat digunakan adalah Payment for Environmental Services (PES) sebagaimana yang diterapkan untuk jasa ekosistem lainnya. Hal ini didukung oleh pendapat Karsenty, Vogel, and Castell (2014) yang menyatakan bahwa PES merupakan salah satu mekanisme insentif yang efektif untuk kredit karbon. Mekanisme tersebut tidak akan mengganggu pemenuhan NDC Indonesia karena pengurangan emisi masih dapat diklaim oleh Pemerintah Indonesia.

Untuk mendukung program pengembangan REDD+ dari sisi pendanaan, pemerintah sedang menyusun Peraturan Pemerintah (PP) tentang Instrument Ekonomi Lingkungan Hidup (IELH) sebagai landasan hukum pembentukan Badan Layanan Umum (BLU) lingkungan hidup. BLU tersebut akan difungsikan sebagai badan independen yang mengatur dana perubahan iklim dari berbagai sumber baik dalam maupun luar negeri. Salah satu tujuan penggunaan dana tersebut adalah untuk menyediakan bantuan finansial kepada para pelaksana REDD+ di lapangan. Bantuan tersebut dapat berupa pinjaman lunak maupun hibah. Tetapi proses penyusunan PP IELH 
tersebut sangat lama sedangkan kegiatan REDD+ di tingkat tapak berkembang cepat dan membutuhkan pembiayaan besar. Sementara itu, perdagangan karbon yang diharapkan dapat menjadi salah satu sumber pembiayaan masih menjadi perdebatan.

Dinamika REDD+ di tingkat global juga memengaruhi perubahan kebijakan REDD+ di tingkat nasional. Sayangnya perubahan kebijakan di tingkat nasional memerlukan waktu untuk proses aktualisasi ke dalam suatu regulasi. Hal ini menyebabkan beberapa kebijakan yang belum diregulasikan bertentangan dengan regulasi yang telah ada sebelumnya. Misalnya, kebijakan larangan perdagangan karbon dari sektor lahan bertentangan dengan Peraturan Menteri Kehutanan (Permenhut) Nomor P.20/MenhutII/2012 tentang Penyelenggaraan Karbon Hutan dan Permenhut Nomor P.50/MenhutII/2014 tentang Perdagangan Sertifikat Penurunan Emisi Karbon Hutan Indonesia. Peraturan tersebut menjadi dasar untuk proses perdagangan karbon baik di dalam maupun di luar negeri sebagai insentif ekonomi bagi para pelaksana REDD+. Bahkan Permenhut Nomor P.20/Menhut-II/2012 mengizinkan penyelenggara usaha karbon untuk memperdagangkan karbon kreditnya maksimal 49\%.

Kondisi tersebut mengindikasikan bahwa sampai saat ini masih diperlukan sinkronisasi kebijakan REDD+ sebelum memasuki fase implementasi penuh. Secara umum, kesiapan REDD+ di tingkat nasional, subnasional dan tapak masih memerlukan proses penguatan untuk dapat memasuki fase full implementation (Butarbutar, 2016). Cronin et al. (2016) Mengungkapkan bahwa kesuksesan pelaksanaan REDD+ di Indonesia memerlukan perubahan besar dalam hal tata kelola dan reformasi kelembagaan.

Selain itu, kebijakan tentang pelarangan perdagangan karbon untuk REDD+ memengaruhi mekanisme insentif ke tingkat tapak. Beberapa inisiasi REDD + di tingkat tapak mengalami stagnasi karena adanya ketidaksinkronan antara keinginan donor untuk mentransfer sertifikat pengurangan emisi dengan kebijakan di tingkat nasional.

Meskipun inisiasi REDD+ di tingkat tapak mengindikasikan penurunan, para pihak di level subnasional dan tapak masih mengharapkan adanya insentif nyata dari pelaksanaan REDD+. Hal ini sejalan dengan hasil penelitian Utomo and Sitorus (2016) yang menyimpulkan bahwa stakeholder yang terkait REDD+ masih memiliki preferensi yang tinggi untuk mendapatkan manfaat langsung terutama penyediaan lapangan kerja serta manfaat tidak langsung dari REDD+. Djaenudin et al. (2016) juga mengungkapkan bahwa pemerintah daerah masih memiliki komitmen untuk mendukung pelaksanaan REDD+.

\section{B. Implementasi REDD+ dan Kepentingan Para Pihak di Tingkat Subnasional}

Kebijakan nasional penurunan emisi diikuti oleh penyusunan Rencana Aksi Daerah Penurunan Emisi Gas Rumah Kaca (RAD GRK) oleh pemerintah provinsi. RAD GRK memuat rencana provinsi untuk menurunkan tingkat emisinya dari berbagai sektor. Pada umumnya, provinsi yang menjadi prioritas percontohan REDD+ telah menyusun RAD GRK. Beberapa provinsi juga membentuk BP REDD+ daerah yang anggotanya terdiri dari berbagai instansi terkait. Lembaga tersebut tidak lagi berfungsi seiring dengan dibubarkannya BP REDD+ nasional. Selain itu kelembagaan tersebut juga tidak didukung oleh mekanisme pendanaan yang jelas. Tidak adanya lembaga REDD+ yang jelas di tingkat provinsi menyebabkan sulitnya koordinasi dan komunikasi pelaksanaan REDD+ dari level nasional ke subnasional. Selain itu, pelaksanaan REDD+ di subnasional menjadi bersifat personal dari pada struktural, tergantung pada komitmen gubernurnya. Ketiadaan lembaga REDD + di tingkat subnasional menjadikan tata kelola dan reformasi kelembagaan REDD+ yang menjadi prasyarat suksesnya REDD+ (Luttrell et al., 
2016) menjadi tidak terpenuhi.

Berdasarkan Undang-Undang

Nomor 23 tahun 2014, urusan kehutanan merupakan kewewenangan pemerintah provinsi. Meskipun demikian, pemerintah provinsi (Pemprov) tidak banyak mengatur pelaksanaan REDD + di tingkat tapak. Pemprov hanya mengidentifikasi kegiatan yang dapat mempertahankan atau meningkatkan stok karbon yang dilakukan oleh seluruh pelaksana pengelola hutan di tingkat tapak. Berbagai kegiatan tersebut dituangkan ke dalam dokumen RAD GRK dan diperhitungkan sebagai upaya Pemprov untuk menurunkan emisinya di sektor kehutanan. Berdasarkan hasil wawancara dengan instansi kehutanan di provinsi, upaya penurunan emisi daerah di sektor kehutanan pada dasarnya merupakan kegiatan yang telah biasa dilakukan dan ditetapkan dalam rencana kinerja pemerintah sesuai dengan pendanaan Anggaran Pemerintah Belanja Daerah (APBD) yang tersedia.

Berdasarkan survei langsung ke lokasi pengembangan DA REDD+, kegiatan REDD+ dapat diklasifikasikan berdasarkan kawasan hutan, yaitu hutan produksi, konservasi dan lindung. Berdasarkan pelaksananya, pelaksana utama REDD+ terbagi menjadi masyarakat, pihak swasta (perusahaan kehutanan), serta pemerintah yang biasanya direpresentasikan oleh pemerintah daerah, pengelola KPH atau taman nasional. Para pelaksana REDD + pada umumnya dibantu atau bekerja sama dengan pihak ketiga baik donator maupun konsultan untuk penyusunan project design document (PDD).

Kegiatan REDD+ merupakan skema global yang harus memenuhi berbagai persyaratan termasuk metodologi. Selain skema global, REDD+ pun harus mengikuti aturan nasional. Sayangnya, perkembangan REDD + baik di tingkat global maupun nasional tidak tersampaikan ke tingkat tapak secara utuh dan cepat. Wibowo (2016) mengungkapkan bahwa sosialisasi sangat diperlukan untuk menyamakan persepsi tentang REDD + di tingkat tapak.

Berdasarkan hasil survei dan wawancara di tingkat tapak, tidak semua program dapat dikategorikan menjadi program REDD+ karena belum memenuhi persyaratan global. KLHK menyebut kegiatan yang belum dapat disebut REDD+ tersebut dengan istilah "kegiatan terkait REDD+" mengingat kegiatan yang dilakukan masih dalam ranah kehutanan. Selain itu, kegiatan REDD + di beberapa provinsi juga belum mengakomodir safeguard.

Selain karakteristik kawasan hutan, tujuan dan kegiatan REDD+ di lapangan sangat ditentukan oleh pelaksananya. Kegiatan di Hutan Lindung (HL) Aek Bual Lombok yang dilakukan oleh masyarakat melalui izin hutan kemasyarakatan adalah agroforestri seluas \pm 100 hektar. Kegiatan tersebut bertujuan untuk meningkatkan kandungan karbon sekaligus hasil hutan bukan kayu yang dihasilkan dapat dimanfaatkan oleh masyarakat. Kegiatan agroforestri ini juga akan bermanfaat dalam menjaga kelestarian daerah aliran sungai (DAS) yang juga menjadi daerah resapan air bagi masyarakat yang tinggal di daerah hilir yaitu sekitar kota Mataram, Lombok.

Kegiatan REDD+ di Aek Bual telah memasuki tahap pembayaran kompensasi dengan menggunakan skema plan vivo. Potensi cadangan karbon baseline di HKM Aek Bual adalah 93,09 ton $\mathrm{C} /$ ha dengan kerapatan 91 pohon/ hektar. Target skenario proyek akan mencapai kerapatan 400 pohon per hektar, dan potensi karbon mencapai 1.542 ton $\mathrm{CO}_{2}$ e per tahun. Hutan Kemasyarakatan Aek Bual telah memberikan manfaat karbon yang terjual tahun 2015 sebesar 381 ton $\mathrm{CO}_{2} \mathrm{e}$, dengan harga karbon 14 USD per ton CO2e.

Kegiatan REDD+ di hutan konservasi yang berupa taman nasional pada umumnya adalah pengamanan hutan dari illegal logging dan kebakaran, konservasi keanekaragaman hayati, serta rehabilitasi zona yang mengalami deforestasiatau degradasibersamamasyarakat. Kegiatan rehabilitasi yang dilakukan berupa agroforestri. Pelaksana REDD+ di TN 
adalah pemerintah pusat sehingga kegiatan yang tercakup dalam program REDD+ pada dasarnya merupakan tugas pokok dan fungsi (TUPOKSI) mereka. Ada tidaknya program REDD+, mereka tetap melaksanakan TUPOKSI sehari-harinya. Hasil wawancara dengan pelaksana menggambarkan bahwa belum ada insentif khusus dari sisi pendanaan anggaran pendapatan belanja nasional (APBN) untuk program REDD+ yang mereka laksanakan.

Di sisi lain mereka menghadapi berbagai kendala di lapangan. Kendala yang sering dihadapi adalah minimnya pendanaan untuk melakukan pengamanan hutan, tingginya resiko kebakaran, masih terjadinya konflik tenurial dengan masyarakat sekitar akibat tata batas yang tidak jelas serta perambahan yang dilakukan oleh masyarakat sekitar. Mereka berharap untuk mendapatkan bantuan pendanaan untuk melaksanakan TUPOKSInya, baik dari sumber APBN maupun dari bantuan donor.

Beberapa pelaksana mendapat bantuan dari donor tetapi mereka tidak memiliki kewenangan penuh untuk mengelola anggaran tersebut. Anggaran donor dikelola oleh donor itu sendiri untuk membantu pelakanaan kegiatan REDD+ secara teknis di lapangan. Beberapa pelaksana merasa donor tidak terbuka dalam melakukan kerja sama, dimana pelaksana bahkan tidak dapat mengontrol apa yang dilakukan oleh donor di lapangan. Donor hanya melakukan koordinasi secara individual dengan petugas dari instansi pelaksana, bukan koordinasi secara institusional. Para donor berlindung pada memorandum of understanding yang ditandatangani di tingkat pusat tetapi tidak diikuti oleh perjanjian teknis di tingkat tapak. Pada beberapa kasus, pelaksana bahkan tidak memahami PDD yang telah disusun oleh donor atau konsultan.

Berdasarkan pengamatan langsung di lapangan, terdapat beberapa kegiatan REDD+ yang mengalami stagnasi karena tidak sejalannya keinginan atau tujuan pelaksana dengan donor. Alasan lain adalah karena donor menghentikan bantuan pendanaan dengan alasan belum ada kejelasan mekanisme benefit sharing dari pengurangan emisi (kredit karbon) yang akan dicapai antara donor dengan Pemerintah Indonesia. Donor berharap mendapatkan sharing kredit karbon yang dapat mereka manfaatkan untuk dijual kembali di pasar internasional atau untuk memenuhi NDC negaranya. Di sisi lain, Pemerintah Indonesia menggariskan bahwa pengurangan emisi dari REDD+ bukan untuk mekanisme perdagangan karbon atau offset tetapi untuk mendapatkan insentif dari negara maju sesuai komitmen Paris Agreement.

Kegiatan REDD+ di hutan produksi dilakukan oleh para pemegang konsesi pengelolaan hutan, baik konsesi hak pengusahaan hutan (HPH) hutan alam, hutan tanaman industri (HTI), restorasi ekosistem, maupun konsesi penyerapan karbon. Kegiatan REDD+ ditujukan untuk mewujudkan kelestarian pengelolaan hutan serta mendapatkan keuntungan ekonomi dari upaya menjaga atau meningkatkan stok karbon di kawasannya. Beberapa kegiatan yang mereka lakukan adalah penanaman pohon kembali (tree replanting), reduced impact logging (RIL), serta penutupan kanal dan rewetting di lahan gambut.

Meskipun demikian, sampai saat ini dari seluruh pelaksana REDD+ di kawasan hutan produksi yang diwawancara belum ada pelaksana yang telah berhasil mendapatkan kompensasi dari program REDD+. Mereka masih dalam tahap negosiasi dengan pembeli karbon di pasar internasional. Mekanisme Carbon Credit dan Registry yang disusun para pelaksana pada umumnya mengacu kepada Voluntary Market - Voluntary Carbon Standard (VCS). Adanya kebijakan larangan perdagangan karbon menjadi salah satu penghambat proses negosiasi.

Ketika mereka dikonfrontasi bahwa pemerintah menggariskan kebijakan REDD+ bukan untuk offset maupun perdagangan karbon, mereka berargumen bahwa dalam surat keputusan (SK) izin pengelolaan 
hutan yang dikeluarkan oleh KLHK, mereka diperbolehkan untuk melakukan perdagangan karbon. Mereka berpendapat bahwa jika pemerintah melarang untuk melakukan perdagangan karbon maka pemerintah melanggar SK tersebut. Mereka juga berharap pemerintah menyediakan mekanisme insentif yang jelas kepada mereka yang telah mengeluarkan biaya operasional untuk persiapan REDD + dan untuk menjaga kawasan hutan apabila perdagangan karbon tidak diizinkan.

Salah satu program REDD+ yang dijadikan percontohan untuk mendapat kompensasi negara maju adalah melalui mekanisme FCPF Carbon Fund (CF) di Kalimantan Timur. Program tersebut dilakukan pada level subnasional dengan pelaksananya adalah Pemerintah Provinsi Kalimantan Timur. Program dimulai pada tahun 2011 dan akan berakhir pada tahun 2025 .

Kegiatan pengendalian emisi dilakukan melalui beberapa strategi dan kebijakan, diantaranya adalah penerapan Reduced Impact Logging di kawasan hutan produksi, penguatan KPH dan pengelolaan hutan bersama masyarakat (PHBM) sebagai frontline pengelolaan hutan di lapangan, konservasi kawasan hutan, dan reformasi perizinan.

Intervensi utama diprediksi mampu mengurangi emisi sebesar 20,5\% dari kondisi BAU atau sebesar 7,4 juta $\mathrm{tCO}_{2} \mathrm{e}$ per tahun di Provinsi Kalimantan Timur (GoI, 2015). Sebanyak 50\% penurunan emisi direncanakan akan dialokasikan untuk kepentingan domestik, sehingga emisi yang dapat dibeli oleh $\mathrm{CF}$ adalah 22 juta $\mathrm{tCO}_{2} \mathrm{e}$. Sertifikat pengurangan emisi yang menjadi hak $\mathrm{CF}$ bersifat retired atau tidak boleh diperjualbelikan kembali.

Dalam pelaksanaannya, pogram $\mathrm{CF}$ menghadapi beberapa kendala diantaranya adalah tidak adanya upfront payment dari FCPF untuk skema CF sehingga investasi disiapkan sendiri oleh pelaksana. Hal tersebut sulit dilaksanakan mengingat anggaran pemerintah yang terbatas. Selain itu, masih terjadinya perbedaan persepsi dan pemahaman stakeholder tentang program pembayaran pengurangan emisi berbasis kinerja.

\section{Gap Analysis antara Kebijakan REDD+ dengan Pelaksanaan di Lapangan}

Untuk melihat adanya ketidaksinkronan atau gap antara kebijakan pemerintah pusat dengan implementasinya di lapangan dibuat matrik yang menggambarkan kebijakan pemerintah atau kondisi ideal yang ingin dicapai, pelaksanaan di lapangan, serta gap antara keduanya. Analisis tersebut didasarkan pada hasil interview, observasi lapangan dan analisis dokumen pendukung.

Berdasarkan Tabel 2 dapat dilihat bahwa gap antara kebijakan di tingkat pusat dengan implementasinya dan kepentingan para pihak di lapangan meliputi hampir seluruh aspek, baik teknis, kelembagaan dan strategis. Peraturan teknis tentang penyelenggaraan karbon hutan dan mekanisme MRV belum dipenuhi oleh sebagian inisiator REDD+. Selain itu hampir semua provinsi yang disurvei sudah tidak memiliki BP REDD+ daerah yang berfungsi untuk melaksanakan kebijakan yang digariskan di tingkat pusat. Pemerintah provinsi menganggap kegiatan yang menjadi cakupan REDD+ sudah dilaksanakan sesuai TUPOKSI institusi masing-masing.

Di pihak lain, pemerintah pusat menggariskan kebijakan REDD + sesuai dengan kesepakatan global. Sayangnya, pemerintah lambat menyusun strategi alternatif untuk mengantisipasi ketidakpastian kesepakatan global dan untuk membangun enabling condition agar kebijakan global dapat diimplementasikan di tingkat lokal.

REDD + merupakan komitmen negara maju dan berkembang di dunia sehingga pelaksanaan REDD+ terkait erat dengan peraturan global yang memerlukan kesepakatan dan kesepahaman bersama antara negara maju dan berkembang. Di sisi lain, kesepakatan negara sangat bergantung pada kepentingan masing-masing pihak. 
Tabel 2. Analisis gap kebijakan nasional REDD+ dengan pelaksanaan di lapangan Table 2. Gap analysis of national REDD+ policy with the implementation in the field

\begin{tabular}{|c|c|c|c|}
\hline $\begin{array}{l}\text { No. } \\
\text { No. }\end{array}$ & $\begin{array}{c}\text { Kebijakan Pemerintah/ } \\
\text { Kondisi Ideal } \\
\text { (Government's Policy/Ideal } \\
\text { Condition) }\end{array}$ & $\begin{array}{l}\text { Pelaksanaan Di Lapangan } \\
\text { (Implementation in the Filed) }\end{array}$ & $\begin{array}{l}\text { Kesenjangan } \\
\text { (Gap) }\end{array}$ \\
\hline 1. & $\begin{array}{l}\text { Program REDD+ memerlukan } \\
\text { pengesahan resmi dari } \\
\text { pemerintah dan memenuhi } \\
\text { peraturan teknis dan } \\
\text { administrasi. }\end{array}$ & $\begin{array}{l}\text { Tidak semua pelaksana yang } \\
\text { menyatakan yang melaksanakan } \\
\text { program REDD+ telah mendapatkan } \\
\text { pengesahan dari pemerintah dan tidak } \\
\text { memenuhi persyaratan administrasi } \\
\text { dan teknis. }\end{array}$ & $\begin{array}{l}\text { - Initiator REDD+ belum } \\
\text { mendapatkan pengesahan dari } \\
\text { pemerintah } \\
\text { - } \\
\text { Peraturan teknis REDD+ belum } \\
\text { dilaksanakan oleh semua initiator } \\
\text { DA REDD+ termasuk mekanisme } \\
\text { MRV dan safeguard }\end{array}$ \\
\hline 2. & $\begin{array}{l}\text { Urusan REDD+ di tingkat } \\
\text { nasional menjadi kewenangan } \\
\text { Ditjen PPI KLHK, dimana } \\
\text { Ditjen PPI menjadi lembaga } \\
\text { resmi sebagai national focal } \\
\text { point untuk urusan perubahan } \\
\text { iklim }\end{array}$ & $\begin{array}{l}\text { BP REDD+ daerah dibubarkan dan } \\
\text { tidak ada lagi kejelasan lembaga } \\
\text { yang berwenang untuk melaksanakan } \\
\text { program REDD+ di daerah. }\end{array}$ & 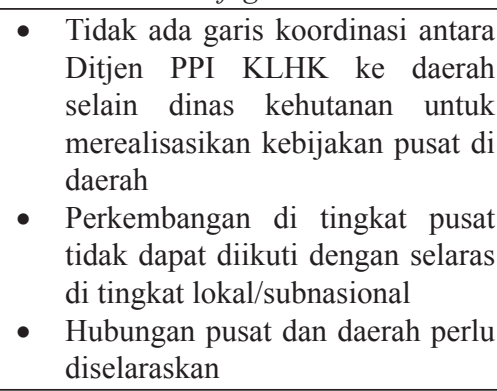 \\
\hline 3. & $\begin{array}{l}\text { REDD+ bukan untuk } \\
\text { mekanisme perdagangan karbon } \\
\text { tetapi insentif dari negara maju } \\
\text { ke negara berkembang melalui } \\
\text { mekanisme performance based } \\
\text { payment sesuai dengan Paris } \\
\text { Agreement artikel } 5 \text { ayat } 2 \text { yang } \\
\text { menyatakan bahwa negara- } \\
\text { negara yang tergabung dalam } \\
\text { United Nations Framework } \\
\text { Convention on Climate Change } \\
\text { (UNFCCC) didorong untuk } \\
\text { melaksanakan mekanisme } \\
\text { performance based payment } \\
\text { dan pendekatan kebijakan } \\
\text { alternatif lainnya untuk } \\
\text { mendukung program REDD+ di } \\
\text { negara-negara berkembang. }\end{array}$ & $\begin{array}{l}\text { - Para pelaksana REDD+ di } \\
\text { lapangan mengharapkan untuk } \\
\text { dapat menjual karbon sebagai } \\
\text { insentif ekonomi. } \\
\text { - Sampai saat ini belum ada insentif } \\
\text { nyata untuk REDD+ baik dari } \\
\text { dalam dan luar negeri, kecuali } \\
\text { program pengelolaan hutan skala } \\
\text { kecil seperti di HKm Aek Bual. } \\
\text { - Izin restorasi ekosistem dan izin } \\
\text { usaha penyerapan karbon (Panrap } \\
\text { Karbon) memperbolehkan } \\
\text { penjualan karbon oleh para } \\
\text { pelaksana usaha (Permenhut } \\
\text { Nomor P.20/Menhut-II/2012 } \\
\text { Tentang Penyelenggaraan Karbon } \\
\text { Hutan). knvensi internasional } \\
\text { Dalam konvensis } \\
\text { belum ada mekanisme yang jelas } \\
\text { reward dan punishment untuk } \\
\text { negara maju yang sudah/tidak } \\
\text { memberikan insentif ke negara } \\
\text { berkembang sehingga kepastian } \\
\text { siapa yang akan memberikan } \\
\text { pembayaran (payment) masih } \\
\text { belum jelas } \\
\text { Pelaksanaan REDD+memerlukan } \\
\text { dana investasi awal yang besar } \\
\text { sedangkan performance based } \\
\text { payment merupakan mekanisme } \\
\text { pembayaran setelah REDD+ } \\
\text { pelaksana berhasil mengurangi } \\
\text { atau menjaga emisinya }\end{array}$ & $\begin{array}{l}\text { - } \text { Terdapat ketidaksinkronan } \\
\text { antara kebijakan REDD+ yang } \\
\text { menjadi domain Ditjen PPI } \\
\text { dengan kebijakan pengelolaan } \\
\text { hutan produksi yang menjadi } \\
\text { domain Ditjen Pengelolaan Hutan } \\
\text { Produksi Lestari (PHPL). } \\
\text { - Kebijakan Pemerintah Pusat } \\
\text { menggunakan pendekatan } \\
\text { konvensi internasional tetapi tidak } \\
\text { melihat kondisi di lapangan. }\end{array}$ \\
\hline
\end{tabular}




\begin{tabular}{|c|c|c|c|}
\hline $\begin{array}{l}\text { No. } \\
\text { No. }\end{array}$ & $\begin{array}{c}\text { Kebijakan Pemerintah/ } \\
\text { Kondisi Ideal } \\
\text { (Government's Policy/Ideal } \\
\text { Condition) }\end{array}$ & $\begin{array}{l}\text { Pelaksanaan Di Lapangan } \\
\text { (Implementation in the Filed) }\end{array}$ & $\begin{array}{l}\text { Kesenjangan } \\
\text { (Gap) }\end{array}$ \\
\hline 4. & $\begin{array}{l}\text { Masih didiskusikan mekanisme } \\
\text { insentif dan sumber pembiayaan } \\
\text { program REDD+ melalui } \\
\text { Draft PP Instrumen Ekonomi } \\
\text { Lingkungan Hidup yang } \\
\text { melandasi pembentukan BLU }\end{array}$ & $\begin{array}{l}\text { Program REDD }+ \text { sudah berjalan } \\
\text { dari tahun 2007, para inisiator sudah } \\
\text { mengeluarkan anggaran cukup } \\
\text { besar. Saat ini inisiator REDD }+ \\
\text { membutuhkan dukungan pendanaan } \\
\text { baik dari mekanisme insentif maupun } \\
\text { perdagangan karbon sedangkan } \\
\text { konsep BLU masih memerlukan } \\
\text { waktu untuk implementasinya }\end{array}$ & $\begin{array}{l}\text { Pemerintah tidak menyiapkan } \\
\text { kebijakan atau strategi alternatif } \\
\text { untuk menanggulangi ketidakpastian } \\
\text { kesepakatan global secara cepat. }\end{array}$ \\
\hline 5. & $\begin{array}{l}\text { Konsep additionality untuk } \\
\text { seluruh kawasan hutan sesuai } \\
\text { dengan kesepakatan global }\end{array}$ & \begin{tabular}{l}
\multicolumn{3}{l}{ Pelaksana REDD+ di kawasan hutan } \\
konservasi menganggap konsep \\
additionality di hutan konservasi \\
kurang cocok karena \\
additionality sedikit
\end{tabular} & $\begin{array}{llr}\text { Kebijakan } & \text { Pemerintah } & \text { Pusat } \\
\text { menggunakan pendekatan } & \text { konvensi } \\
\text { internasional tetapi tidak } & \text { melihat } \\
\text { kondisi di lapangan. } & \end{array}$ \\
\hline 6. & $\begin{array}{l}\text { Entitas merupakan pelaksana } \\
\text { utama program REDD+, donor } \\
\text { merupakan partner untuk } \\
\text { mendukung pendanaan atau } \\
\text { peningkatan kapasitas sumber } \\
\text { daya manusia (SDM) }\end{array}$ & $\begin{array}{l}\text { Donor mendominasi pelaksanaan } \\
\text { program dan pelaksana tidak } \\
\text { menguasai program. Donor } \\
\text { beranggapan Memorandum of } \\
\text { Understanding (MoU) di tingkat pusat } \\
\text { merupakan legalitas untuk melakukan } \\
\text { kegiatan di lapangan tetapi tidak } \\
\text { ditindaklanjuti dengan perjanjian } \\
\text { kerja sama dan komunikasi intensif di } \\
\text { tingkat tapak }\end{array}$ & $\begin{array}{l}\text { Bantuan donor untuk pelaksanaan } \\
\text { REDD+ belum efektif }\end{array}$ \\
\hline 7. & $\begin{array}{l}\text { Target penurunan emisi } 29 \% \\
\text { dan } 41 \%\end{array}$ & $\begin{array}{l}\text { Belum ada aturan dan pemilahan } \\
\text { alokasi program untuk memenuhi } \\
\text { target } 29 \% \text { dan } 41 \% \text { serta untuk } \\
\text { mekanisme offset }\end{array}$ & $\begin{array}{l}\text { Tidak ada kejelasan aturan pemenuhan } \\
\text { target } 29 \% \text { dan } 41 \%\end{array}$ \\
\hline 8. & $\begin{array}{l}\text { Penerapan SRN (sistem } \\
\text { registrasi nasional) untuk } \\
\text { memonitoring program } \\
\text { penurunan emisi di Indonesia }\end{array}$ & $\begin{array}{l}\text { - } \text { Belum ada aturan yang } \\
\text { mewajibkan pelaksana program } \\
\text { penurunan emisi untuk melakukan } \\
\text { registrasi. } \\
\text { - Sosialisasi kurang sehingga } \\
\text { pelaksana belum antusias untuk } \\
\text { meregisterkan programnya }\end{array}$ & $\begin{array}{l}\text { Belum ada peraturan yang jelas untuk } \\
\text { mendukung kebijakan SRN sehingga } \\
\text { belum efektif berjalan }\end{array}$ \\
\hline 9. & $\begin{array}{l}\text { SRN digunakan sebagai } \\
\text { alat untuk mengidentifikasi } \\
\text { dan memonitor penurunan } \\
\text { karbon dalam negeri. Jika ada } \\
\text { sertifikat penurunan karbon } \\
\text { yang diperdagangkan di pasar } \\
\text { internasional tetapi tidak } \\
\text { diregisterkan di SRN maka } \\
\text { Pemerintah Indonesia tidak } \\
\text { akan mengakuinya. Hal ini } \\
\text { diharapkan akan mengurangi } \\
\text { adanya offset karbon dari } \\
\text { Indonesia untuk negara lain } \\
\text { (karena tidak ada pengesahan } \\
\text { dari pemerintah Indonesia } \\
\text { secara resmi) }\end{array}$ & 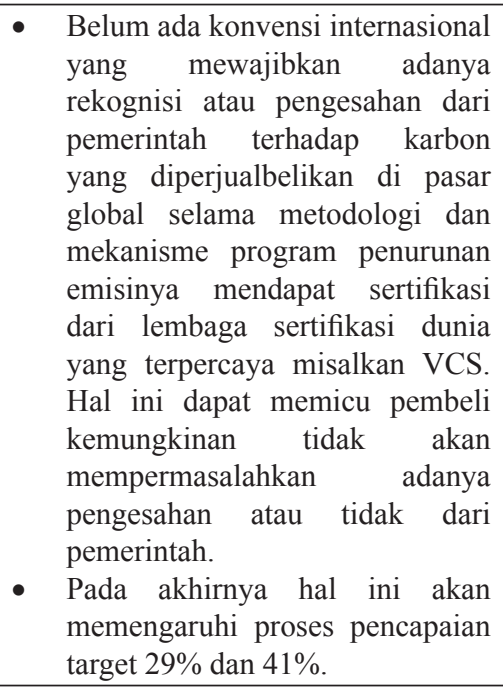 & $\begin{array}{l}\text { Kebijakan SRN belum efektif untuk } \\
\text { mencapai tujuannya }\end{array}$ \\
\hline
\end{tabular}

Sumber (Source): Data primer, diolah (Primary data, processed). 
Murdiyarso (2010) memaparkan bahwa perundingan terkait perubahan iklim di tingkat global sangat berliku dan diwarnai oleh kepentingan masing-masing negara. Wibowo (2016) mengungkapkan bahwa masih terdapat ketidakpastian dalam skema global REDD+ terutama mekanisme insentif yang menyebabkan menurunnya inisiasi REDD+ di tingkat tapak.

Disamping itu, kesepakatan internasional kadang-kadang diartikan berbeda-beda oleh masing-masing negara. Sebagai contoh, Pemerintah Indonesia menganggap bahwa mekanisme pembiayaan REDD + adalah performance based payment sebagaimana dalam artikel 5 Paris Agreement. Hal tersebut berarti negara maju wajib memberikan insentif kepada negara berkembang yang berhasil menurunkan emisinya tanpa ada timbal balik karbon kredit yang diklaim negara maju. Alasan tersebut menjadi alasan proses penandatanganan Letter of Intent (LoI) FCPF World Bank mengalami stagnasi. Di pihak lain, beberapa negara berkembang seperti Congo, Vietnam, dan Costa Rica yang tergabung dalam program FCPF telah menandatangani LoI FCPF terkait jual beli karbon kredit yang dihasilkan dari program FCPF. Hal tersebut mengindikasikan negaranegara tersebut membolehkan perdagangan karbon atau offset dalam REDD+.

Hasil analisis gap memberikan gambaran adanya ketidaksinkronan antara kebijakan di level nasional dengan kepentingan para pihak di level subnasional dan tapak. Banyak dan rigidnya persyaratan teknis dan administratif pelaksanaan REDD+ menjadi hambatan di tingkat lapangan. Hal tersebut sebenarnya sudah diungkapkan oleh Godden, Kallies, Rodney, and Jacqueline (2010) bahwa potensi hambatan pelaksanan REDD+ adalah detail teknis pelaksanaan REDD + akibat terlalu banyak mekanisme yang dipersayaratkan utuk REDD+.

Selain itu, terdapat gap antara proses perumusan kebijakan di level nasional yang membutuhkan waktu lama dengan dinamika perkembangan REDD + di level subnasional dan tapak. Apabila hal ini terus berlangsung maka kemungkinan yang terjadi adalah tidak terkontrolnya pelaksanaan REDD + di tingkat tapakatau semakinhilangnya dukungan dilevel subnasional dan tapak untuk melaksanakan program pengurangan emisi di sektor lahan. Konsekuensi keduanya adalah sulitnya pemenuhan NDC Indonesia mengingat sektor lahan merupakan penyumbang terbesar emisi Indonesia.

\section{KESIMPULAN DAN SARAN}

\section{A. Kesimpulan}

REDD+ merupakan pendekatan kebijakan untuk menjaga hutan secara lestari tetapi hasilnya menunjukkan adanya ketidakefektifan instrumen kebijakan untuk mengatur pelakanaan REDD+. Terdapat ketidaksinkronan antara kebijakan yang ditetapkan di level nasional dengan kepentingan para pihak di level subnasional dan tapak. Hal tersebut menjadi salah satu penyebabnya terhambatnya pelaksanaan REDD+ di Indonesia.

Penyebab utama ketidaksinkronan tersebut adalah tidak ditetapkannya lembaga yang jelas dan memiliki otoritas terhadap pelaksanaan REDD+ di daerah yang dapat menjembatani komunikasi dan koordinasi antara pemerintah pusat, pemerintah provinsi dan para pelaku REDD+ di tingkat tapak. Faktor lain adalah lambatnya perumusan regulasi di level nasional untuk menyikapi ketidakpastian dan dinamika kesepakatan terkait REDD+ di tingkat global dan perkembangan kegiatan REDD+ di tingkat tapak. Hal penting lainnya adalah tidak adanya alternatif mekanisme pendanaan dan insentif REDD+ di dalam negeri. Selain itu sosialisasi kebijakan di level nasional ke tingkat regional dan lokal belum terlaksana dengan baik. Terhambatnya pelaksanaan REDD+ akan memberikan konsekuensi negatif dalam pencapaian NDC nasional. 


\section{B. Saran}

Untuk meningkatkan sinkronisasi para pihak di berbagai level, penelitian ini memberikan rekomendasi sebagai berikut:

- Menyederhanakan peraturan terkait persyaratan teknis dan administratif pelaksanaan REDD+ di tingkat tapak.

- Memperkuat tugas dan peran Unit Pelaksana Teknis (UPT) Direktorat Jenderal PPI KLHK utuk melaksanakan koordinasi dan komunikasi kebijakan dan strategi REDD+ dari dan ke tingkat subnasional dan tapak. Penguatan tugas dan peran tersebut harus diikuti oleh dukungan pendanaan.

- Memperkuat tugas dan peran Satuan Kerja Pemerintah Daerah (SKPD) yang memiliki akses dan komunikasi yang baik dengan gubernur dalam pelaksanaan REDD+ di daerah. Alternatif lain adalah membangun lembaga baru yang bertugas untuk percepatan pelaksanaan REDD+ di daerah yang berada di bawah otoritas gubernur secara langsung.

- Perlu adanya skema insentif dan pendanaan dalam negeri untuk mendukung pelaksanaan REDD + di tingkat subnasional dan tapak.

- Meningkatkan sosialisi strategi dan kebijakan REDD+ ke tingkat subnasional dan tapak.

\section{UCAPAN TERIMA KASIH (ACKNOWLEDGEMENT)}

Penulis mengucapkan terima kasih kepada penggiat DA REDD+ yang telah memberikan kontribusi data dan informasi selama pelaksanaan kegiatan penelitian. Penulis juga memberikan apresiasi terhadap para reviewer yang memberikan masukan konkrit.

\section{DAFTAR PUSTAKA}

ADB. (2010). National REDD+ strategies in Asia and the Pacific: Progress and challenges. Retrieved 15 June 2016 from www.adb.org. Manila.
Angelsen, A., Brockhaus, M., Kanninen, M., Sills, E., Sunderlin, W. D., \& Wertz-Kanounnikoff, S. (2009). Realising REDD+: National strategy and policy option. Bogor, Indonesia: CIFOR.

Angelsen, A., \& McNeill, D. (2012). The Evolution of REDD+. In A. Angelsen, M. Brockhaus, W. D. Sunderlin, \& L. V. Verchot (Eds.). Analysing REDD +: Challenges and choices (pp. 31-48). Bogor: CIFOR.

Avishek, K., Yu, X., \& Liu, J. (2012). Ecosystem management in Asia Pacific: Bridging sciencepolicy gap. Environmental Development, 3, 77-90. doi:10.1016/j.envdev.2012.03.014

Barr, C., Resosudarmo, I. A. P., Dermawan, A., Mccarthy, J. F., Moeliono, M., \& Setiono, B. (2006). Decentralization of forest administration in Indonesia: Implications for forest sustainability, economic development and community livelihoods. Bogor: CIFOR.

Butarbutar, T. (2016). Catatan kesiapan Indonesia untuk skema pengurangan emisi dari deforestasi dan degradasi hutan. Jurnal Analisis Kebijakan Kehutanan, 13(2), 103-125.

Colfer, C. J. P., Dahal, G. R., \& Capistrano, D. (2008). Lessons from forest decentralization: Money, justice and the quest for good governance in Asia-Pacific. London: Earthscan.

Cronin, T., Santoso, L., Di Gregorio, M., Brockhaus, M., Mardiah, S., \& Muharrom, E. (2016). Moving consensus and managing expectations: Media and REDD+ in Indonesia. Climatic Change, 137(1), 57-70. doi:10.1007/s10584-0151563-3

Departemen Kehutanan. (2010). Strategi REDD Indonesia fase readiness 2009-2012 dan progress implementasinya. Jakarta: Departemen Kehutanan.

Djaenudin, D., Lugina, M., Ramawati, Kartikasari, G., Indartik, Pribadi, M.,A, \& Astana, S. (2016). Perkembangan implementasi pasar karbon hutan di Indonesia. Jurnal Analisis Kebijakan Kehutanan, 13(3), 159-172.

Godden, L., Kallies, A., Rodney, K., J, \& Jacqueline, P. (2010). Reducing emissions from deforestation and forest degradation in developing countries. Monash University Law Review, 139.

GoI. (2015). Forest carbon partnership facility. Emission reduction program idea note. Jakarta, Indonesia: Government of Indonesia.

Gupta, J., Van der Grijp, N., \& Kuik, O. (2013). Climate change, forest and REDD: Lesson for institutional design. London: Routledge.

Human Rights Watch. (2009). 'Wild Money': The human rights consequences of illegal logging and corruption in Indonesia's forestry sector. 
Retrieved 15 June 2016 from www.hrw.org.

Karsenty, A., Vogel, A., \& Castell, F. (2014). Carbon rights, REDD+ and payments for environmental services. Environmental Science and Policy, 35, 20-29.

Levin, K., McDermott, C., \& Cashore, B. (2008). The climate regime as global forest governance: Can reduced emission from deforestation and forest degradation (REDD) initiatives pass a 'dual effectiveness' test? Int. For. Rev, 10(3), 538-549.

Luttrell, C., Resosudarmo, I.A.P., Muharrom, E., Brockhaus, M., \& Seymour, F. (2014). The political context of REDD+ in Indonesia: Constituencies for change. Environmental Science and Policy, 35, 67-75. doi:10.1016/j. envsci.2012.10.001

Luttrell, C., Sills, E., Aryani, R., Ekaputri, A. D., \& Evnike, M. F. (2016). Who will bear the cost of REDD+? Evidence from subnational REDD+ initiatives. Retrieved 15 June 2016 from www.cifor.org.

Moeliono, M., Wollenberg, E., \& Limberg, G. (2009). The decentralization of forest governance: Politics, economics and the fight for control of forests in Indonesian Borneo. London: Earthscan.

Murdiyarso, D. (2010). Perubahan iklim: Dari obrolan warung kopi ke meja perundingan dalam perubahan iklim \& tantangan peradaban. PRISMA: Majalah Pemikiran Sosial Ekonomi. 29(2), 23-33.

Nurtjahjawilasa, Duryat, K., Ysman, I., Septiani, Y., \& Lasmini. (2013). Modul: Konsep REDD+ dan implementasinya. Jakarta: The Nature Conservancy.
Purnomo, H., Suyamto, D., Abdullah, L., \& Irawati, R. H. (2012). REDD+ actor analysis and political mapping: An Indonesian case study. International Forestry Review, 14(1), 74-89.

Sugiyono. (2008). Metode penelitian kuantitatif, kualitatif, dan R\&D. Bandung: Bandung Alfabeta.

Utomo, N.A, \& Sitorus, S.R.P. (2016). Sinergi tata ruang terhadap pelaksanaan REDD+: Studi kasus di Kabupaten Katingan, Kalimantan Tengah. Jurnal Penelitian Sosial dan Ekonomi Kehutanan, 13(3), 165-176.

Venter, O., \& Koh, L. P. (2012). Reducing emissions from deforestation and forest degradation (REDD+): game changer or just another quick fix? (Report). Annals of the New York Academy of Sciences, 1249, 137-150.

Vijge, M. J., Brockhaus, M., Di Gregorio, M., \& Muharrom, E. (2016). Framing national REDD+ benefits, monitoring, governance and finance: A comparative analysis of seven countries. Global Environmental Change, 39, 57-68.

Wibowo, A. (2016). Implementasi kegiatan REDD+ pada kawasan konservasi di Indonesia. Jurnal Analisis Kebijakan Kehutanan, 13(3), 185199.

Wibowo, A., \& Salminah, M. (2016). Implementasi demonstration activity REDD+ untuk mendukung kebijakan pengendalian perubahan iklim. (Laporan Hasil Penelitian). Bogor: P3SEKPI. 